\title{
Study of Routing Protocols for Vehicular Ad hoc Network
}

\author{
Jhilam Biswas \\ Department of Electronics \& \\ Communication, \\ Manipal Institute of Technology, \\ Manipal
}

\author{
Shreya Singh \\ Department of Electronics \& \\ Communication, \\ Manipal Institute of Technology, \\ Manipal
}

\begin{abstract}
The vehicular ad hoc network (VANET) is an emerging new technology. Developing multi-hop routing protocols for urban VANETs is a challenging task. VANETs are a kind of Wireless ad hoc network that usually has a routable networking environment on top of a Link Layer ad hoc network. In this paper, we first analyze the unique features of urban VANET and then we move on to discuss the various VANET routing protocols which already have been proposed. We also analyze and compare the various protocols based on some common parameters.
\end{abstract}

\section{General Terms}

VANET, routing protocols, metrics of comparison

\section{Keywords}

VANET, DSDV, DSR, AODV, GPSR, MIBR

\section{INTRODUCTION}

Vehicular ad hoc network is a type of MANET [2] (Mobile ad hoc network).It is a technology that uses moving cars as nodes to create a mobile network. VANET turns every participating car into a wireless router to connect. MANET is a selfconfiguring infrastructure less network of mobile devices connected by wireless. There are various routing protocols which have been suggested in VANET, though not implemented practically.

We first start by discussing the proactive and reactive routing protocols, then we go on to discuss the various parameters of comparison. Finally we compare all these protocols based on some common parameters.

\section{THE FEASIBILITY OF VANET}

For VANET routing protocols to work effectively, there should be adequate number of vehicles on the city roads at any given time. Any given vehicle should be within range of at least another one vehicle to establish a link and to prove multi hopping routing practical.

\section{BRIEF DESCRIPTION OF THE ROUTING PROTOCOLS IN VANET}

Based on the available routing theories available in MANET, routing protocols can be broadly sub-divided under two categories- Proactive and Reactive Routing protocols. Destination-Sequenced Distance Vector (DSDV) protocol falls into the proactive ones. It broadcasts message packets periodically and each node maintains the routes to all other nodes in the network. On the contrary, Dynamic Source
Routing (DSR) protocol is a typical reactive routing protocol, which sets up the links to form the network only when there is a demand to do so.

\subsection{DSDV Routing Protocol}

In DSDV, each mobile node of an ad hoc network maintains a routing table, which lists all available destinations, the metric and next hop to each destination and a sequence number generated by the destination node. Using such routing table stored in each mobile node, the packets are transmitted between nodes of an ad hoc network. Each node of the ad hoc network updates the routing table with advertisement periodically or when significant new information is available to maintain the consistency of the routing table with the dynamically changing topology of the ad hoc network.

\subsection{DSR Routing Protocol}

DSR provides excellent performance for routing in multi-hop ad hoc. It has a very low routing overhead. It has the ability to deliver almost all originated data packets, even with rapid motion of all nodes. When node $\mathrm{P}$ wants to send a packet to node $\mathrm{Q}$, but does not know a route to $\mathrm{Q}$, node $\mathrm{P}$ initiates a route discovery. Node P floods Route Request (RREQ). Each RREQ [1] has sender's address, destination's address and a unique Request ID determined by the sender. Each node appends its own identifier when forwarding RREQ. Every node transmitting the packet is responsible for confirming that the packet has been received by next hop.

\subsection{MIBR Routing Protocol}

MIBR (Mobile Infrastructure Based VANET Routing Protocol) is a location based reactive routing protocol. It's a novel protocol which makes full use of the buses, making them a key component in route selecting and packet forwarding. Significant performance improvement in terms of packet delivery ratio and throughput is achieved using MIBR. It estimates the density of each road segment based on the bus line information for road segment selection and prefers buses to ordinary nodes as the forwarding node. The MIBR protocol includes two essential parts: 1) selecting an optimal route which consists of a sequence of road segments with the best estimated transmission quality, and 2) efficiently forwarding packets hop-by-hop through each road segment in the selected route. 


\subsection{AODV (AD HOC ON Demand Distance Vector) Routing Protocol}

It's a Reactive on demand protocol consisting of three phases: 1) Routing Discovery 2) Data Transmission 3) Route Maintenance. When a source node wants to send packets to a destination node with no routes to the destination node in its routing table, the route discovery phase will be started. The source node broadcasts a Route Request (RREQ) packet to its neighbor. The neighbors that receive the RREQ packet are divided into three categories: the receiver node is the destination node; the receiver node has a route to destination and none of the both.

In the first two situations, the receiver node produces a Route Reply (RREP) packet and sends it back to the preceding node that forwards the RREP packet. And the RREP packet will finally get to the source node across the route that RREQ packet traverses, and then the source node obtains a route or some routes to the destination node.

In the third situation, the receiver node forwards the RREQ packet to its neighbors until the destination node receives the RREQ packet or a node has a route to the destination node, and the same process happens. After establishing connection, data transmission occurs. If any error is there, Route Error (RERR) packet is sent back. Problems faced in this protocol are: 1) RREQ packet is flooded to a large part of the network, and thus, large bandwidth consumption. 2) VANET is highly dynamic, hence source always chooses newest route (newest sequence no) or with less hops. Overall, AODV is better in VANET as well as MANET, because of its ability to react to network changes quickly.

\subsection{GPSR (Greedy perimeter stateless routing)}

It is a position based routing (reactive type). In GPSR [5], vehicles are assumed to be equipped with GPS (Global Positioning System) to know about their own geographic location. Its major drawback is that it uses greedy forwarding scheme, which depends on accurate position info, rapid movement of vehicles- change in position and so inaccurate info may cause to select next-hop which is out of transmission range and ultimately discard packets at expiration of TTL, so high loss. IMPROVED GPSR STRATEGY is new protocol wherein vehicles equipped with GPS and sensors for vehicle velocity and intelligent devices for computing capacity. In this three schemes are incorporated which are as follows:

A) Neighboring Table Update Scheme- Using Hello packets, the network learns accurately about one-hop neighbors (various fields in Hello Packets)

B) Next Hop Selection Scheme- Set priority if any of the following occurs: 1) nodes are in direction of destination 2) relative speed between neighbor node and current node is less or equal to $10 \mathrm{~m} / \mathrm{s}$

C) Recovery Scheme- When local max happens then perimeter forwarding mode. "Store-to-forward": packets are temporarily stored at moving nodes while waiting for opportunities to forward those. When can't find a suitable neighbor, forwarded to "Quorum"-where a selected subset of nodes keeps track of all/some node position updates.

\subsection{Improved AODV Routing Protocol}

To make route more stable, Improved AODV is used. Mobility parameters, which calculate speed and direction, are used here.

A) Selecting nodes with more stable links in $1^{\text {st }}$ phase [3] Source node gets the speed and direction information of its neighbors. Link weight calculation is made of the node with all its neighbors. The formula is given by:

Link weight $=\mathrm{Wv} * \mid \mathrm{Vi}-\mathrm{V}$ neighbor of $\mathrm{I}|+\mathrm{WD} *| \mathrm{Di}-$ D neighbor of I

Where $\mathrm{Wv}$ is the speed weight factor, $\mathrm{Vi}$ is the speed of node,

$\mathrm{V}$ neighbor of I is the speed of node I's neighbor node, WD is the direction weight factor, $\mathrm{Di}$ is the direction of Node I, D neighbor of $I$ is the direction of node I's neighbor node[5] Links with similar speed and same direction will be more stable. An appropriate number bound is set. If number bound is less than number of neighbor, source node chooses number bound of its neighbors and if it's more, it sends RREQ to all neighbors.

B) Selecting more stable route in route selection process: if confusion between choosing a route to destination Using Route Expiration Time (RET): Choose route with longest lifetime. Source chooses route with min RET Using total weight route: Destination generates RREP packet, adds its one speed and direction and sets total route weight to zero. Source finally receives and chooses route with min weight. This protocol will be more effective if VANET is combined with large scale network and cognitive radio network.

\section{PARAMETERS OF COMPARISON, METRICS USED}

The following metrics are used to evaluate the performance of the various proposed routing protocols in Low, High and Middle density region.

\subsection{Average End To End Delay}

It is the time difference between ' $t$ ' and ' $t 1$ '

Where t: time when a packet was released from a source node. $\mathrm{t} 1$ : time when the same packet reached the next node, towards its destination. This delay should be as minimum as possible. Nodes should be close to one another to minimize this delay.

\subsection{Throughput and Packet Delivery Ratio}

Throughput is a measure used to determine the efficiency of the network. Packet delivery ratio refers to the ratio of the number of packets finally received at the destination node to the number of packets transmitted from the source node. Higher the ratio, better is the VANET network environment. Packet Delivery Ratio $=(\mathrm{DR} / \mathrm{DS}) * 100$

Where $D R=$ Data packets received by the agent at destination node, $D S=$ Data packets Sent by the agent at source node [5] 


\subsection{Effect of speed of nodes and the number of nodes}

These are very important parameters to decide the performance of a VANET routing protocol. Greater speed of nodes might not be favorable since it may lead to frequent link breakage amongst nodes. At higher node speeds, it is difficult to predict to which node a forwarding packet will go. Thus a packet may not be delivered to the destination node faithfully [3]. Also, more the number of nodes, better chances of making a strong linked network within the VANET environment.

\section{TABLE OF COMPARISON}

We now compare the various protocols discussed above (DSDV, DSR, MIBR, AODV, IMPROVED AODV, GPSR) based on some common metrics mentioned above. Some assumptions were made for the actual simulation process. It was assumed that road conditions was ideal while conducting the experiments. Uniform traffic condition was assumed. We have chosen freeway mobility model for our simulation scenario [4]. Also we have considered that no intersection is there. The tabular column gives the distinctive feature of each of the protocol which have been proposed till now for a VANET network. We can thus compare the routing protocols and finally come up with useful results which can be of use in future.

Table1: Table comparing all the protocols against different parameters

\begin{tabular}{|c|c|c|c|c|c|c|}
\hline $\begin{array}{l}\text { Parameter of } \\
\text { Comparison }\end{array}$ & DSDV & DSR & MIBR & AODV & $\begin{array}{l}\text { Improved } \\
\text { AODV }\end{array}$ & GPSR \\
\hline \multirow{3}{*}{$\begin{array}{l}\text { Average End } \\
\text { to End Delay }\end{array}$} & $\begin{array}{l}\text { It is smaller } \\
\text { compared to } \\
\text { DSR }\end{array}$ & \multirow{3}{*}{$\begin{array}{l}\text { It is very } \\
\text { high }\end{array}$} & \multirow{3}{*}{$\begin{array}{l}\text { Very less } \\
\text { compared to } \\
\text { DSDV and } \\
\text { DSR }\end{array}$} & $\begin{array}{l}\text { Low (for low } \\
\text { and medium } \\
\text { traffic) }\end{array}$ & \multirow{3}{*}{ Not tested. } & \multirow{3}{*}{ Not tested. } \\
\hline & $\begin{array}{l}\text { High (for low } \\
\text { and medium } \\
\text { traffic) }\end{array}$ & & & \multirow{2}{*}{$\begin{array}{c}\text { High (for low } \\
\text { and High } \\
\text { traffic) }\end{array}$} & & \\
\hline & $\begin{array}{l}\text { Low (for low } \\
\text { density traffic) }\end{array}$ & & & & & \\
\hline $\begin{array}{c}\text { Throughput } \\
\text { and Packet } \\
\text { delivery get } \\
\text { ratio }\end{array}$ & Low & $\begin{array}{l}\text { Higher than } \\
\text { DSDV }\end{array}$ & $\begin{array}{l}\text { Significant } \\
\text { improvement } \\
\text { compared to } \\
\text { DSR and } \\
\text { DSDV. }\end{array}$ & High & Very High & Highest \\
\hline $\begin{array}{c}\text { Effect of speed } \\
\text { Of } \\
\text { nodes/vehicles }\end{array}$ & Not tested & $\begin{array}{l}\text { Has the ability } \\
\text { to deliver } \\
\text { packets } \\
\text { faithfully even } \\
\text { when node } \\
\text { speeds are high }\end{array}$ & $\begin{array}{l}\text { Speed of nodes } \\
\text { has no } \\
\text { significant } \\
\text { effect on } \\
\text { performance. }\end{array}$ & $\begin{array}{l}\text { Leads to more } \\
\text { broken links }\end{array}$ & $\begin{array}{l}\text { Leads to less } \\
\text { broken links }\end{array}$ & $\begin{array}{l}\text { Leads to some } \\
\text { Routing } \\
\text { Overhead }\end{array}$ \\
\hline $\begin{array}{c}\text { Effect of } \\
\text { number of } \\
\text { nodes/ vehicles }\end{array}$ & Not tested & $\begin{array}{c}\text { Has no } \\
\text { significant } \\
\text { effect on } \\
\text { performance. }\end{array}$ & $\begin{array}{l}\text { Leads to more } \\
\text { effective } \\
\text { packet } \\
\text { transmission }\end{array}$ & $\begin{array}{l}\text { Leads to } \\
\text { increased } \\
\text { number of } \\
\text { unconnected } \\
\text { links }\end{array}$ & $\begin{array}{l}\text { Higher the } \\
\text { number of } \\
\text { nodes, better is } \\
\text { the packet } \\
\text { delivery. }\end{array}$ & $\begin{array}{l}\text { Lesser broken } \\
\text { links }\end{array}$ \\
\hline
\end{tabular}




\section{EXPERIMENTAL RESULTS}

In general, with the increase in velocity of the nodes, average end to end delay decreases, get ratio of the network decreases and the route cost also increases. This is shown in the following graphs with respect to DSDV and DSR.

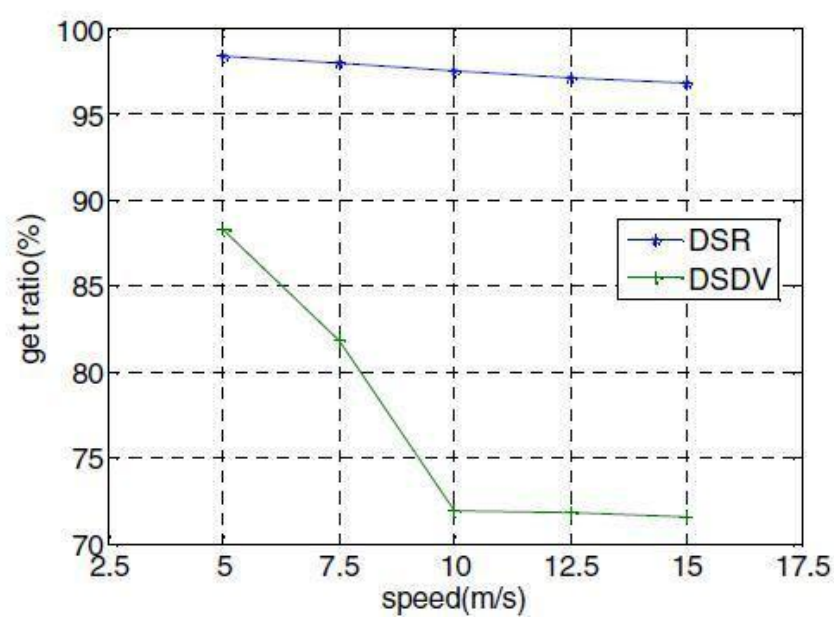

Figure1: Comparison of speed against Get ratio in case of DSR and DSDV [3]

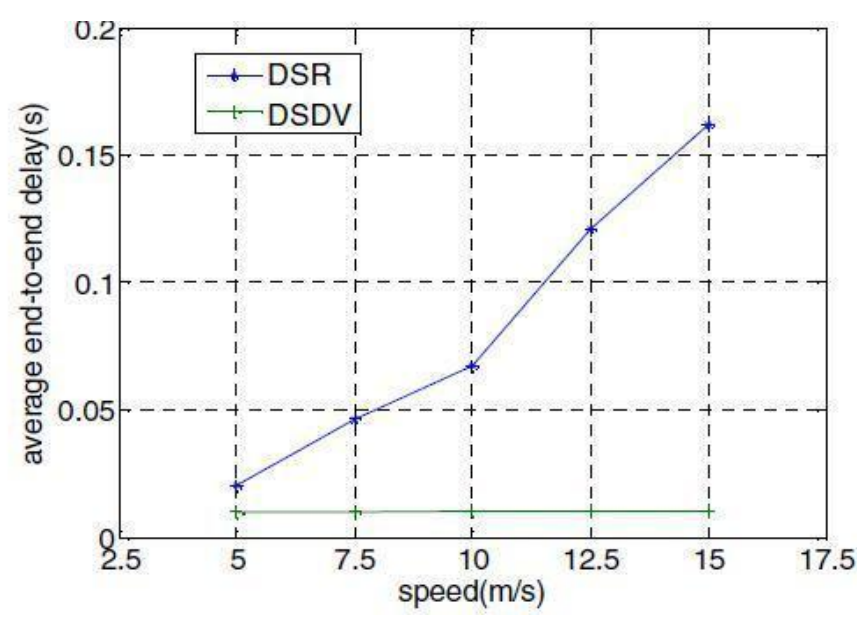

Figure2: Comparison of speed against Average end-to-end delay of DSR and DSDV [1]

Observing the behavior of packet delivery ratio (PDR) and end to end delay, we see that AODV gives better PDR consistently compared to DSDV protocol. The proactive (table-driven) protocols have decreasing PDR all the time. It is also observed that DSDV has its acceptability for city's low density variation only. DSDV performance was observed satisfactory for all traffic levels.

The routing protocol MIBR takes advantage of the buses as a mobile backbone. This leads to low algorithmic complexity compared to other protocols. Deployment of this protocol is very easy since it doesn't use any static nodes. MIBR achieves the highest packet delivery ratio, because buses are given a higher priority than ordinary cars, when it comes to selecting the next hop destination.

Comparing AODV, Improved AODV and GPSR, we see that
GPSR leads to some routing overhead due to increased speed of noes unlike in AODV and Improved AODV. But GPSR has highest throughput capability when compared to other protocols. Also, GPSR has lesser broken links in a high density traffic environment. AODV on the other hand has very minimal end to end delay. These facts are shown in the following graphs.

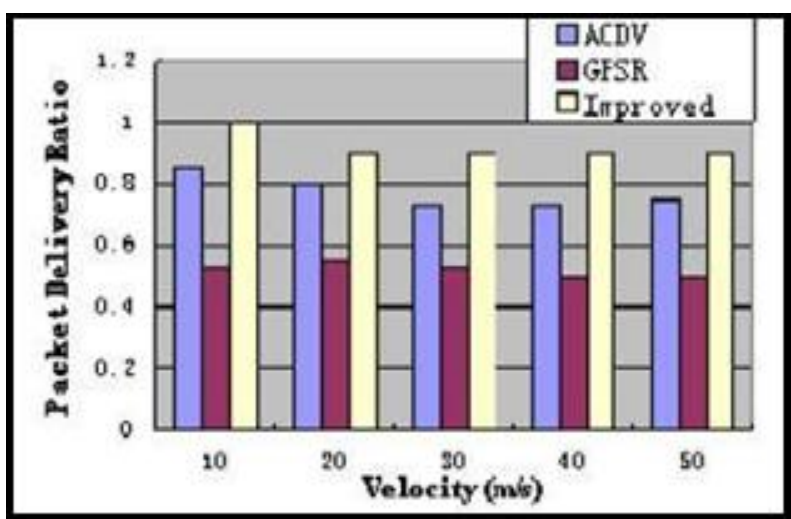

Figure3: Comparison of PDR against velocity with respect to AODV, Improved AODV and GPSR [2]

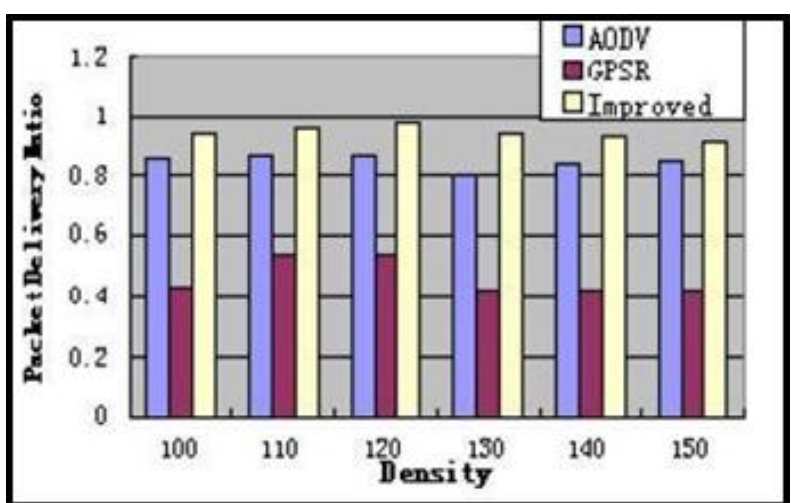

Figure4: Comparison of PDR against vehicular density with respect to AODV, Improved AODV and GPSR [2]

\section{CONCLUSION}

This paper briefs all the routing protocols which have been majorly proposed (both reactive and proactive) in the domain of VANET. It has also given an overall comparison amongst all the protocols. Each suggested protocol is unique in its own way and has its own distinct features. This comparison would be of immense help to researchers helping them to come up with a new protocol which combines all the positive features of the above protocols. The study of VANET is a booming area of research. Advancement in this domain is still a very big challenge. As the future work, more realistic metrics into the routing protocol, such as, direction of moving nodes, angle at which they move and even the history information of vehicular traffic can be incorporated. 


\section{REFERENCES}

[1] Journal of Information Science and Engineering 26, 913932 (2012) "Routing Protocols in Vehicular Ad Hoc Networks: A Survey and Future Perspectives"

[2] Kevin C. Lee, UCLA, USA, Uichin Lee, UCLA, USA, Mario Gerla, UCLA, USA. March 2011. "Survey of Routing Protocols in Vehicular Ad Hoc Networks"

[3] Mingliu Zhang and Richard S. Wolff. May 2011"Routing Protocols for Vehicular Ad Hoc Networks in Rural Areas"

[4] Jie Li, Hisao Kameda. March 2010. "Study of the Feasibility of VANET and its Routing Protocols"

[5] "Destination Discovery Oriented Position Based Routing in VANET" 2011 International Conference on Wireless Communication
[6] "A Mobile Infrastructure Based Routing Protocol in the Urban Environment" 2010 International Conference on Communications and Mobile Computing

[7] Yu, Y., Lu, G.-H., and Z.-L. Zhang (2010) "Performance Analysis of Optimized VANET Protocols in Real World Tests".

[8] Zhao, J.; Cao, G. (2009) “An Improved AODV Routing Protocol for VANETs"

[9] Charles E. Perkins, Ad Hoc Networking, AddisonWesley, 2011

[10] Perkins, C. E. and Royer, E. M. (2012), "Ad-Hoc OnDemand Distance Vector Routing," Proc. IEEE WMCSA '12, New Orleans, LA, Feb. 2012. 